\title{
A Study on the Utilization of the Earthworms Eisenia fetida and Eisenia andrei for the Disposal of Polymers
}

\author{
Hyunseong Kim
}

\begin{abstract}
Disposing plastics has been an incredibly arduous task. Many of the plastics that people use take tens of hundreds of years to decompose. Yet, plastic usage increases year by year. Plastics have actually become a part of people's lives, from water bottles to the exterior of televisions. To eliminate the usage of plastics would be impossible. Therefore, methods for effectively disposing plastics are necessary. However, the existing models are rather too inefficient or are too expensive. To incinerate plastics would be environmentally harmful, while to implement high level technology would not be popular when it comes to expenses. Therefore, we planned to propose a solution that would consider both cost and efficiency. We decided to use earthworms since they not only best satisfied our standards, but also are able to eat a variety of materials, including organic materials, inorganic materials, and various wastes. Under this basis, we placed five different powders of the polymers Polyethylene, Polymer Nylon, Polypropylene, Ethylene vinyl acetate, and Linear low-density polyethylene into the soil, and used two different types of earthworms (Eisenia fetida and Eisenia andrei). With our experiment set, we carefully observed the activity of the earthworms and the change in mass of each polymer.
\end{abstract}

Index Terms - Eisenia fetida, Eisenia andrei, polymer, plastic disposal.

\section{INTRODUCTION}

\section{A. Aim of Study}

Plastic recycling has been a major issue. As plastic usage expands in quantity and diversity, the amount that is discarded has risen proportionately. However, environmentally friendly methods of disposing these plastics are limited both economically and technologically. Americans discard 33.6 million tons of plastic each year, but only 14.2 percent is handled [1]. The rest becomes dumped in landfills, laying waste upon the land and the soil. Concerned about this issue, we chose to delve into the topic of purification of land that has been polluted by plastic waste. We decided to approach this issue with an effective and cost efficient method. Our approach was to use earthworms, as they are known to improve soil fertility [2], [3]. Since earthworms can be used in several cases, such as dealing with the heavy metals in soil, we deduced that they can also be used in dealing with the unhandled plastics in the soil [4], [5]. Under these motives, we began to precede our experiment.

Manuscript received April 14, 2015; revised June 25, 2015.

Hyunseong Kim is with the International Department of the Hankuk Academy of Foreign Studies, Yongin, South Korea (e-mail: kim111@daum.net).

\section{B. Purpose of Study}

Our experiment had two purposes. First was to observe the efficiency of the earthworms Eisenia fetida and Eisenia andrei in the purification of soil polluted by plastics. The other was to observe how efficiently the earthworms decompose plastics according to the plastic type. Our experiment expanded with these purposes.

\section{Initial Hypothesis}

Under the observed fact that earthworms are excellent decomposers of organic and inorganic waste, we hypothesized that earthworms would have the potential to be applied in the decomposition of untreated polymers. Thus, if the vermicomposting earthworms Eisenia fetida and Eisenia andrei are injected into soil that is contaminated by untreated polymers, then the mass of the polymers in the soil will decrease since the earthworms will intake the polymers along with the soil.

\section{BACKGROUND CONTENT}

\section{A. Earthworms}

Earthworms, in general, are tube-shaped, segmented animals commonly found in soil that feed on live and dead organic matter. Earthworms are hermaphrodites, having both male and female sex organs. They are also invertebrates, maintaining their structure through coelom chambers that act as a hydrostatic skeleton. The digestive system of earthworms runs through the entire body, and large numbers of chemoreceptors are located near the mouth. Circumferential and longitudinal muscles line the gut, and these muscles move the digesting food toward the worm's anus. Similar muscles on the periphery of each segment enable the worm to move [6].

Earthworms vary in size. An adult earthworm can be from $10 \mathrm{~mm}$ long and $1 \mathrm{~mm}$ wide to $3 \mathrm{~m}$ long and over $25 \mathrm{~mm}$ wide. Earthworms also vary in habitat. Usually, though, earthworms tend to not live in exceptionally dry or cold places. Moist conditions are usually necessary for earthworms. Although most earthworms live at or under the surface of the soil, other factors influence their choice of habitat, such as climate and vegetation [7].

\section{B. Digestive System of Earthworms}

The digestive system extends from the mouth to the anus. It is differentiated into a buccal cavity, pharynx, esophagus, crop, gizzard, and intestines. The muscular walls of the pharynx draw in food, and the pharynx secretes mucus. When food moves into the esophagus, calcium is pumped in to maintain the calcium levels between the blood and the food. 
Strong muscular contractions and the help of mineral particles ingested along the food allows for the digestion of the food. The intestine secretes pepsin to digest proteins, amylase to digest polysaccharides, cellulase to digest cellulose, and lipase to digest fats. The intestinal walls contain blood vessels where the digested food is absorbed and transported throughout the body. Earthworms are able to eat a variety of organic material. These include dead leaves and other dead plant material. They are also able to eat some living plants, dead animals, manure, and tiny animals in the soil [8].

\section{Benefits to the Soil}

Earthworms have many benefits to the soil. Earthworms firstly improve the physical structure of soil. As a result, they improve water filtration rates and absorption rates, helping the soil to drain better. The tunneling activity of earthworms also improves soil aeration, porosity, and permeability.

Earthworms also improve soil fertility. Earthworms do this by bringing up minerals from deep in the subsurface that are often in short supply in surface layers. They also do this by eating litter and removing it from the soil surface. By eating soil, earthworms create vermicompost [9]. Vermicompost has a significant effect on improving soil fertility. As earthworms eat litter, they leave the nutrients in their casting, ready to be used for plants. Plant growth stimulants such as Auxins are also produced in the castings, and these hormones stimulate roots to grow faster and deeper. Vermicompost can be thus used as a nonpolluting natural fertilizer, or a $\mathrm{pH}$ neutralizer, since the product that comes out of the back end of a worm is more neutral in $\mathrm{pH}$ than what goes in the front end. Earthworms also contribute to the soil in other ways. Earthworms chelate nutrients, making chemically unavailable minerals available to plants. The bacteria that live in earthworm guts can fix nitrogen, as greater rates of nitrogen fixation are found in casts compared to surrounding soil.

Earthworms are also able to eliminate dangerous chemicals. The bacteria in the gut help destroy harmful chemicals and breakdown organic wastes. Microbes living in worms have the ability to breakdown complex organic molecules like cellulose and lignin. Moreover, researchers have found that the bacteria detoxify many hazardous chemicals such as hexachlorocyclohexane $(\mathrm{HCH})$.

\section{Utilized Earthworms}

Eisenia fetida, also known as the Redworm and the Dungworm, is a species of earthworm adapted to decaying organic material. These earthworms thrive in rotting vegetation, compost, and manure. It is found extensively around the world and live in diverse habitats and not only in the ground. Eisenia fetida is one of the most commonly used earthworms for vermicomposting. These earthworms have a length of $35-130 \mathrm{~mm}$ and have a diameter of $3-5 \mathrm{~mm}$ [10].

Eisenia fetida is epigean, meaning that it lives near the soil surface. It lives on the surface of the soil or in the top 10 inches of the topsoil under the litter layer. As Eisenia fetida is a commercial species, it is commonly found in vermicomposting bins or on worm farms. However, as it is an epigeic composter, it can be often found in the woods within the ground cover of the leaves. Otherwise it is found in manure piles on farms or fields. It is therefore adapted to many different climates, including variable temperatures, moisture contents, and pH levels [11]. Eisenia fetida has a similar digestive system as other worms. It has the same structure as that of earthworms and also has a digestive system that is connected from the mouth to the anus

Eisenia andrei is a close relative of Eisenia fetida. Like its sibling species, it is epigeic, preferring to live in compost or leaf litter rather than mineral soils. In comparison to Eisenia fetida, Eisenia andrei is darker in color, and has less visible stripes. Although its status as a separate species was fully confirmed by molecular analyses, Eisenia andrei is still often misidentified and confused with Eisenia fetida.

\section{MATERIALS AND PROCEDURE}

\section{A. Materials}

For the study, we prepared a plastic container and some schales for storage, a Digital Electronic Scale WK-4C, Diamond Model 500 and electron scale for mass measurement, some filter paper and nitric acid for filtration, the earthworm species Eisenia fetida and Eisenia andrei, some soil, and the polymers Polypropylene, Polyethylene, Linear low-density polyethylene, Nylon, and Ethylene-Vinyl Acetate.

\section{B. Procedure}

We first moved the earthworms into the plastic container. There were 6 plastic containers. We placed one as the control group. The other five were set as the variable group. With plenty of earthworms available, we placed about 200 earthworms into each container. Combined with the soil, we balanced the mass to 600 grams.

We then put the polymers into the plastic containers filled with the earthworms. We put in one type of polymer per container. We mixed the soil with the polymer to create the conditions we wanted for the experiment. Each container was marked with the polymer it contained. We also checked the mass change of each plastic container.

Next, we placed the worms, soil, and polymers into the schales. We took this approach in order to conduct a more precise experiment. Several steps were required for each schale. We placed the schale on the small mass meter. The device automatically set the mass to zero. We then poured 5 grams of soil onto the schale

Then, we placed the top of the schale on the small mass meter and poured the polymer, balancing the mass to 1 gram. We mixed the polymer and the soil. Then, we again placed the top of the schale on the small mass meter. We put in about 5 grams of worms (=7 or 8 worms) on the schale. We placed the worms into the soil. We repeated this process five times, since there were five types of polymers.

We regularly checked the mass change of each schale. For this, we observed the change in the mass of the worms, the change in the mass of each schale. We further investigated the number of dead worms

Last, in order to observe the change in the mass of the polymers, we used filtration methods. We first separated the earthworms, and then prepared filter paper. We dripped some water, and then filtered, repeating this step several times. We then performed a $2^{\text {nd }}$ filtration using a $200 \mathrm{~mL}$ beaker and a 
cone. Next, we added nitric acid to dissolve unnecessary waste. Then, we conducted a 3th filtration using another $200 \mathrm{~mL}$ beaker, a cone, and some filtration paper. Lastly, we dried the filter paper, and obtained the polymers. These steps were repeated for each polymer.

\section{Initial Conditions}

We first fixed the initial total mass to 11 grams, which consisted of 5 grams of earthworms, 5 grams of soil, and 1 gram of polymer. We then made measurements on a 3 day basis for 12 days, as shown in Table I.

TABLE I: INITIAL MASS OF EACH MATERIAL

\begin{tabular}{llllll}
\hline \hline Material & $\begin{array}{l}\text { Initial } \\
\text { Total } \\
\text { Mass }\end{array}$ & $\begin{array}{l}\text { Initial } \\
\text { Earthworm } \\
\text { Mass }\end{array}$ & $\begin{array}{l}\text { Initial } \\
\text { Soil Mass }\end{array}$ & $\begin{array}{l}\text { Initial } \\
\text { Polymer } \\
\text { Mass }\end{array}$ \\
\hline 1 & P.E & 11 & 5 & 5 & 1 \\
2 & E.V.A & 11 & 5 & 5 & 1 \\
3 & Nylon & 11 & 5 & 5 & 1 \\
4 & P.P & 11 & 5 & 5 & 1 \\
5 & L-LDPE & 11 & 5 & 5 & 1 \\
\hline \hline
\end{tabular}

\section{RESULTS}

\section{A. Total Mass of the Schales}

After 12 days, we found that the total mass had decreased in the schales, as shown in Table II.

TABLE II: The ChANGE IN MASS OF EACH SchalE

\begin{tabular}{llllll}
\hline \hline & Day 1 & Day 3 & Day 6 & Day 9 & Day 12 \\
\hline P.E & 11 & 9.4 & 7.3 & 6.8 & 6.4 \\
E.V.A & 11 & 10.1 & 9.7 & 8.7 & 7.8 \\
Nylon & 11 & 10.5 & 9.6 & 8.9 & 7.5 \\
P.P & 11 & 10.4 & 9.3 & 8.6 & 7.4 \\
L-LDPE & 11 & 9.1 & 7.5 & 6.8 & 5.9 \\
\hline \hline
\end{tabular}

\section{B. Change in Mass of Earthworms}

We then observed the change in the mass of the earthworms, and saw a significant change, as shown in Table III.

TABLE III: CHANGE IN THE MASS OF THE EARTHWORMS

\begin{tabular}{llllll}
\hline \hline & Day 1 & Day 3 & Day 6 & Day 9 & Day 12 \\
\hline P.E & 5 & 4.4 & 3.1 & 2.4 & 2.1 \\
E.V.A & 5 & 4.5 & 3.9 & 2.7 & 2.3 \\
Nylon & 5 & 4.3 & 3.9 & 2.5 & 1.9 \\
P.P & 5 & 4.1 & 3.7 & 2.3 & 1.8 \\
L-LDPE & 5 & 3.4 & 2.5 & 2.1 & 1.8 \\
\hline \hline
\end{tabular}

\section{Change in Combined Mass of Soil and Polymer}

There was also a change in the combined mass of the soil and the polymers, as shown in Table IV.

TABLE IV: CHANGE IN THE SOIL AND POLYMER MASS

\begin{tabular}{llllll}
\hline \hline & Day 1 & Day 3 & Day 6 & Day 9 & Day 12 \\
\hline P.E & 6 & 5.1 & 4.2 & 3.8 & 3.6 \\
E.V.A & 6 & 5.8 & 5.8 & 5.6 & 5.3 \\
Nylon & 6 & 5.8 & 5.7 & 5.5 & 5.4 \\
P.P & 6 & 5.7 & 5.6 & 5.4 & 5.3 \\
L-LDPE & 6 & 5.3 & 5 & 4.8 & 4.5 \\
\hline \hline
\end{tabular}

\section{Change in the Polymer Mass}

We carefully observed the change in the polymer mass, as that was the focus of our experiment, as shown in Table V.
TABLE V: CHANGE IN THE POLYMER MASS

\begin{tabular}{llllll}
\hline \hline & Day 1 & Day 3 & Day 6 & Day 9 & Day 12 \\
\hline P.E & 1 & 0.7 & 0.6 & 0.6 & 0.5 \\
E.V.A & 1 & 0.8 & 0.5 & 0.4 & 0.4 \\
Nylon & 1 & 0.7 & 0.6 & 0.5 & 0.5 \\
P.P & 1 & 0.6 & 0.4 & 0.3 & 0.2 \\
L-LDPE & 1 & 0.6 & 0.3 & 0.2 & 0.2 \\
\hline \hline
\end{tabular}

\section{E. Health Condition of Earthworms}

We lastly observed the fates of the earthworms. None of the earthworms died during the experiment, and every earthworm showed some movement. However, the intensity of movement differed. There was relatively weak movement in the earthworms in the schales of L-LDPE and PE. There was relatively moderate movement in the earthworms in the schales of EVA. There was relatively strong movement in the earthworms in the schales of Nylon and PP.

\section{DISCUSSION}

\section{A. Analysis}

In the experiment conducted in the plastic containers, there were two groups, a control group and a variable group. We observed a decrease in the mass of both groups. One of the main reasons for the decrease was the earthworms. There are two explanations for this phenomenon. Firstly, the lack of moisture forced the earthworms to lose moisture. As earthworms are composed of more than $99 \%$ water, they must live in moist conditions. Although we kept the schales shut, the lack of moisture made the earthworms become drier than they were initially, making them lose mass. The second reason was due to the basal metabolism of the earthworms. As the earthworms conducted metabolism, they consumed energy. Like most organisms, the consumption of energy was also a factor that made the earthworms lose mass.

We also observed the behavior of the earthworms before and after inserting the polymers. We saw that even after the polymers were added, the earthworms did not change behavior. This meant that earthworms do not particularly avoid the polymer powder. Thus, earthworms do not have any specificity towards polymers, and consume them as they would consume soil.

The experiment conducted in the schales was to figure out specifically if the polymers would have a toxic effect on the earthworms. However, this was not the case for the earthworms. All of the earthworms remained alive, even after the experiment. However, the intensity of movement and the quickness of response differed from polymer to polymer. In general, the earthworms demonstrated slower movement for polymers that had low density and required more amounts of powder. Nevertheless, we saw that the polymers we used, which are those that are commercially used widely, did not have any detrimental effects on the earthworms.

The second objective of the experiment was to observe if the earthworms would favor consuming some polymers over others. However, this was not exactly the case. The large variety of the earthworm's diet comes from its nonselective attitude. Correspondingly, the change in the mass of the polymers stayed relatively the same. This meant that 
earthworms do not have a preference when it comes to polymers.

\section{B. Effects on the Environment}

The earthworms were able to purify the soil. However, the mechanism was not digestion because the polymers remained in the bodies of the earthworms. [8] It was rather through polymer dispersion. The earthworms were able to consume the polymers without rejecting them. By deploying these earthworms, they could lessen the polymer concentration of highly contaminated soil. At the same time, substances excreted by the earthworms would also aid in the purification of such areas. [12]

The expenses of this method were relatively small. We placed 5 grams of earthworms, which was approximately 5 to 7 earthworms. As 2000 earthworms cost approximately 30 dollars, the expense to decomposing ratio was relatively low. Coupled with their high reproduction rate, earthworms can be a solution that considers both cost and efficiency. Furthermore, polymers do not have any detrimental effects on earthworms. Through an optimal ratio of earthworms and polymer, polymer disposal can be possible through the usage of earthworms.

\section{CONCLUSION}

Tackling the question of whether or not earthworms are effective organisms for disposing plastics, we concluded that earthworms can be a potential solution to the issue of plastic disposal. Through the investigation of earthworms, we found that they are benefactors to the soil in two ways. Firstly, earthworms are able to eat a variety of substances, which allows them to rid the soil of harmful waste. Secondly, they benefit the soil by producing vermicompost. We took a step further by implementing these aspects to the disposal of plastics. Through experimentation, we observed a gradual change in the mass of not only the polymers, but also the earthworms. Although the experiment began with the motive of investigation whether earthworms could be a potential solution, we were able to extend our experiment by observing the effects of the polymers on the earthworms. The decrease in the mass of the polymers showed that earthworms can be a potential solution to the issue of plastics disposal. Furthermore, the observation of the earthworms showed that polymers do not have a toxin effect on earthworms. The cost and efficiency of the vermicomposting earthworms Eisenia fetida and Eisenia andrei allow them to be commercially implemented to the plastics-disposal industry.

\section{REFERENCES}

[1] Plastic Recycling Is A Work in Progress, New York Times, March 30, 2002.

[2] P. H. F. Hobbelen, J. E. Koolhaas, and C. A. M. Gestel, "Bioaccumulation of heavy metals in the earthworms lumbricus rubellus," Thesis, Department of Animal Ecology, Faculty of Earth and Life Sciences, Vrije Universiteit Amsterdam, De Boelelaan 1085, 2006.

[3] J. Scullion and A. Malik, "Earthworm activity affecting organic matter, aggregation and microbial activity in soils restored after opencast mining for coal," Soil Biology and Biochemistry, pp. 119-126, 2000.

[4] P. Uzoije, A. L. Uzoigwe, E. Otuonye, C. O. Kamalu, and A. Onunkwo-Akunne, "Modeling lateral distribution of heavy metal and bio-accumulation in earthworm in the varying acidic surface horizon of waste-polluted soil," Thesis, Department of Environmental Engineering, Federal University of Technology Owerri, 2013.

[5] D. J. S. purgeon, S. P. Hopkin, and D. T. Jones, "Effects of cadmium, copper, lead and zinc on growth, reproduction and survival of the earthworm Eisenia fetida (Savigny): Assessing the environmental impact of point-source metal contamination in terrestrial ecosystems," Environmental Pollution, 1992.

[6] M. Blaxter, "Nematodes: The worm and its relatives," PLoS Biol., vol. 9, no. 4, 2011.

[7] L. A. Weaver, T. J. Lysyk, and M. J. Clapperton, "The influence of soil moisture and temperature on the survival, aestivation, growth and development of juvenile Aporrectodea tuberculata (Eisen) (Lumbricidae)," Pedobiologia, pp. 121-133, 2000.

[8] K. S. Wu, "On the physiology and pharmacology of the earthworm gut," The Journal of Experimental Biology, vol. 16, pp. 184-197, 1939.

[9] N. Senesi, "Composted materials as organic fertilizers," The Science of the Total Enviroment, vol. 81, no. 82, pp. 521-542, 1989.

[10] R. Fadaee, "A review on earthworm Esienia fetida and its applications," Scholars Research Library, vol. 3, no. 5, pp. 2500-2506, 2012.

[11] M. O. Apolinario, E. S. Corrria, and A. S. Souto, "Utilization of earthen worm eisennia fetida in the feeding of penaeus vannamei post lavas," 1998.

[12] E. Tohidinejad, H. Madani, and M. Jenabi, "Organic fertilizers and vermicompost," Shahid Bahonar University of Kerman Publications, p. 150, 2011.

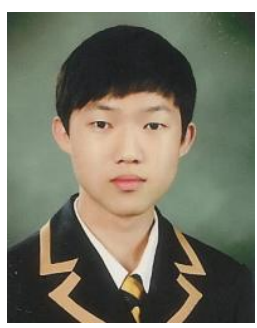

Hyunseong Kim was born in Seoul, South Korea and currently he attends the International Department of the Hankuk Academy of Foreign Studies. He has a strong interest in chemistry and biochemistry. Currently, he is undergoing an intensive physics course in order to gain a stronger background on chemistry. He wishes to get a career as a professor or as a researcher for medical firms that research medication and vaccines. 